\title{
Aşıya rağmen gelişen bir tetanoz vakası: Erken başlangıç ve iyi seyir
}

\author{
A tetanus case developing despite vaccination: Early onset and good prognosis \\ Şafak Kaya*, Özcan Deveci, Mustafa Kemal Çelen, Ali Tardu, Fatma Ukil, Ünal \\ Beyazıt, Sedat Kaya, Hatice Çil, Şehmuz Kaya, Nazif Elaldı
}

Enfeksiyon Hastalıkları ve Klinik Mikrobiyoloji Kliniği (Dr. Ş. Kaya, Doç. Dr. Ö. Deveci, Dr. M. K. Çelen), Genel Cerrahi Kliniği (Dr. A. Tardu, Dr. Ü. Beyazıt), Anestezi Kliniği (Dr. F. Ukil, Dr. S. Kaya), Nöroloji Kliniği (Dr. H. Çil), Gazi Yaşargil Eğitim Araştırma Hastanesi, TR-21000 Diyarbakır, Ortopedi ve Travmatoloji Kliniği (Dr. Ş. Kaya), Van Bölge Eğitim Araştırma Hastanesi, TR-65100 Van, Enfeksiyon Hastalıkları ve Klinik Mikrobiyoloji Anabilimdalı (Prof. Dr. N. Elaldı), Cumhuriyet Üniversitesi Tıp Fakültesi, TR-58140 Sivas

\section{Özet}

Perianal bölgesinden yaralanan 26 yaşında erkek hasta genel cerrahi servisinde takip edilirken kasılmaları olması nedeniyle tarafımızdan konsülte edildi. İnşaat işçisi olan hasta iki gün önce perianal bölgeden demir bir çubukla yaralanmış ve aynı gün acil servisde sadece tetanoz aşısı yapılmıştı. Hastaya klinik olarak tetanoz tanısı konuldu ve yoğun bakıma alındı. Hastaya 5000 Ü insan tetanoz immünglobulini uygulandı. Kasılmaları olması nedeniyle diazepam infüzyonu başlandı. Hastaya yatışında metronidazol başlanmıştı ve tedaviye devam edildi. Takibinde mekanik ventilatör ihtiyacı duyabileceği düşünülerek başka bir merkeze sevk edilen hastanın 7 gün takip sonrası komplikasyon gelişmeksizin taburcu edildiği öğrenildi. Sonuç olarak; tetanoz uygun aşılamayla önlenebilmesine rağmen günümüzde hala sorun olan bir enfeksiyondur. Yaralanma sonrası tetanoz gelişebileceği akılda tutulmalı ve tetanoz aşısının yanısıra immünglobulin uygulamasının da yapılması korunma da önemlidir.

Anahtar sözcükler: Tetanoz, kasılma, immünglobulin

\begin{abstract}
A 26 year-old man who were followed up in a general surgical service as a result of perineal injury was consulted by us due to muscle spasms. The patient was a construction worker and had injured by an iron bar from the perianal region two days ago. In emergency department, tetanus vaccine had been only applied in same day. He was diagnosed as tetanus and admitted to intensive care unit. He was given $5000 \mathrm{U}$ human tetanus immune globulin. Intravenous diazepam was given for muscle spasms. Intravenous metronidazole had been applied since the first day of hospitalization. We thought that he might need mechanical ventilation, therefore, patient was referred to another hospital. It was learned that patient had no complications and he was discharged on the 7th day of hospitalization. In conclusion, tetanus is still a problematic infection, although it can be prevented by vaccination. It should kept in mind that tetanus may develop after injury and in addition to tetanus vaccine, application of immune globulin is also important.
\end{abstract}

Keywords: Tetanus, spasm, 1mmune globulin

Geliş tarihi/Received: 09 Kasım 2013; Kabul tarihi/Accepted: 21 Kasım 2014

*İletişim adresi:

Dr. Şafak Kaya, Enfeksiyon Hastalıkları Anabilm Dalı, Diyarbakır Eğitim ve Araştırma Hastanesi, TR-21010 Diyarbakır. E-posta: ksafak76@gmail.com 


\section{Giriş}

Tetanoz, Clostridium tetani toksini ile meydana gelen, akut başlangıçlı, tonik kasılmalarla seyreden, mortalitesi yüksek bir infeksiyon hastalığıdır. C tetani, Gr (+), zorunlu anaerop, terminal sporlu, hareketli, kapsülsüz bir basildir. Doğada yaygın olarak tozda, toprakta, hayvan ve insan dışkısında, bazen sularda daha çok dış etkilere dayanıklı olan sporlu form halinde bulunmaktadır. Oksijensiz ortamlarda çoğalıp toksin salgılayan bakteri, oksijenli ortamlarda sporlanır. Hastalığın oluşması için bakterinin vejetatif forma dönüşmesi ve toksin salgılaması gereklidir. Kirli ve nekrotik yaralarda, beraberinde aerop bakteri infeksiyonu da mevcutsa ortamdaki oksijen miktarı azalacağından sporların vejetatif hale geçmesi daha kolay olmaktadır. Peptid yapıda bir nörotoksin olan tetanospazmin, hastalığın klinik belirtilerinden sorumludur [1]. Tetanospazmin alfa motor nöronların nöromusküler kavşağından sinir sistemine girer. Toksin buradan retrograt transport ile nöronal hücrelerin gövdesine ulaşır. Spinal kord veya beyin sapına gelen toksin, hücre dışı boşluğa ve buradan da presinaptik inhibitör hücrelere geçer. Bu hücreler transmitör olarak glisin ve GABA kullanmaktadır. Toksin tarafından transmitör salınımının engellenmesiyle disinhibisyon oluşur ve kas tonusu artarak rijidite meydana gelir. Motor sistem gelen uyarılara tetanik spazm denilen, agonist ve antagonist kasların aynı anda kasıldığ 1 şiddetli ve sürekli kasılmalarla cevap verir. C. tetani'nin ikinci toksini tetanolizin ise bakterinin çoğalmasından ve hemolizden sorumludur [2-3]. Hastalığın jeneralize, lokalize ve sefalik olmak üzere üç klinik formu vardır. Jeneralize tetanoz en sık görülen formdur. Tanı esas olarak oyku ve fizik muayene ile konulur. Yaralanmadan ortalama 15 gün (2 gün-2 ay) sonra ilk semptomlar ortaya cıkar. İnkübasyon süresinin kısalığı olumsuz yönde bir prognostik faktordur [2, 4]. Tetanoz olgularının tedavisinde tetanik spazmların önlenmesi hastanın prognozu açısından hayati öneme sahiptir. $\mathrm{Bu}$ nedenle kasılmaların en kısa zamanda durdurulması için müdahale gerekir [5].

Araştırmamızda perineal bölgeden yaralanan ve genel cerrahi servisinde takip edilmekte iken yatışının ikinci gününde tetanoz gelişen bir olguyu immünizasyonun önemini bir kez daha vurgulamak amaciyla sunduk.

\section{Olgu sunumu}

Yirmi altı yaşında erkek hasta iki gün önce perine yaralanması nedeniyle genel cerrahi servisine yatırılmıştı. Hastanın inşaat işçisi olduğu iki gün önce perineal bölgeden demir bir çubuğun saplandığı, aynı gün acil servise başvurduğu ve burada tetanoz aşısı yapıldığ öğrenildi. Yatışının ikinci gününde tonik kasılmaları olan hastanın yakınlarının odaya girmesi durumunda şikayetlerinde artiş olması nedeniyle önce konversif olduğu düşünülmüştü. Daha sonra yaralanmadan dolayı tetanoz olabileceği düşünülerek kliniğimizden görüş istenen hastaya üç yıl önce yine yaralanma sonrası tek doz tetanoz aşısı yapıldığı öğrenildi. Genel durum orta, bilinç açık, oryante ve koopere olan hastanın fizik muayenesinde; pupiller izokorik, solunum takipneik (25/dak.), ateş $37,2{ }^{\circ} \mathrm{C} /$ aksiller ve kalp atımları taşikardik (128/dak.) idi. Alt ve üst extremitelerde fleksiyon, yaygın rijidite, istemli hareketlerde kısıtlllık ve ense sertliği vard1. Perine bölgesinde $2 \mathrm{~cm}$ çapında temiz suture lezyonu mevcuttu. Hastaya ampirik seftriakson 1 g 2x1 IV ve metronidazol $500 \mathrm{mg}$ 4x1 IV tedavi başlanmıştı. Hasta yoğun bakım ünitesi (YBÜ)'ne loş ve sakin bir odaya alındı. İnsan tetanoz immünglobulini 5000 Ü IM olarak uygulandı. Takibinde kasılmaları devam eden hastaya diazepam infüzyonu başlandı. Ertesi gün mekanik ventilasyon ihtiyacı olabileceğinden hasta üniversite hastanesine sevkedildi. Buradaki takipleri esnasinda ek bir tedavi uygulanmasina gerek duyulmayan hasta komplikasyon gelişmeksizin bir hafta sonra şifa ile taburcu edildi.

\section{Tartışma}

Tetanoz, aşılama çalışmalarına rağmen gelişmekte olan ülkelerde hala sorun olmaya devam eden bir hastalıktır. Dünyada her yıl yaklaşık bir milyon yeni olgu görüldüğü tahmin edilmektedir. Yeni doğan ve yaşlı hastalarda mortalite \%50'nin üzerindedir. Gelişmekte olan ülkelerde mortalitesi yüzbinde 28 gibi yüksek bir orana sahiptir [2]. 
Tetanozun inkübasyon (kuluçka) periyodu, yani yaralanmadan sonra ilk semptomların oluşmasına kadar geçen süre, 2 gün ile 2 ay, ortalama 15 gündür. Başlangıç süresi olarak ilk semptomlarla ilk refleks spazm arasında geçen zaman kabul edilmektedir ve bu süre 1-4 gün olarak kabul edilmektedir [1]. Olgumuzda ilk temastan 2 gün sonra semptomlar başlamış olduğundan kuluçka süresi 2 gün olarak kabul edilmiştir. İnkübasyon süresinin kısalığı olumsuz yönde bir prognostik faktördür. Ergönül ve ark.'nın [4] yaptığ1 çalışmada şikayetler ortaya çıktıktan 48 saat sonra müdahale edilen hastalarda mortalite $\% 82$ iken, 24 saat içinde müdahale edilenlerde oran \%46,6 olarak tespit edilmiştir. Bizim olgumuzda inkübasyon süresi 2 gün kadar kısa bir süre olmasına rağmen prognozu iyiydi. Biz de bunun tetanoz immünglobulininin erken dönemde yapılmasına bağlı olabileceğini düşünmekteyiz. Hastamızın hastanede takibi yapılırken kasılmalarının ortaya çıkması erken müdahale şansımızı arttırmıştı. Tetanoz gelişme olasılığı olan ve olmayan yaralar arasında kesin ayrım yapılamadığı için birincil immünizasyonu tam olmayan veya on yıldan daha uzun süredir tetanoz aşısı yapılmayan yaralanmalar ile immünizasyon durumu bilinmeyen tüm açık yaralanmalarda, tetanoz aşısı ile birlikte immünglobulinin de yapılması önerilmektedir [6]. Bizim vakamıza yaklaşık 3 yıl önce yine yaralanma nedeniyle tek doz tetanoz yapılmıştı. Tetanoza karşı duyarlı olduğu anlaşılan olgumuza aşıyla birlikte immünglobulin de uygulanması gerekirdi. Özellikle acil ünitesinde görev yapan personelin bilgi eksikliğini gidermek amacıyla bu konuda eğitimler verilmesinin önemli olduğunu düşünmekteyiz.

Tetanoz farklı klinik tablolarla ortaya çıkabildiğinden ve nadir görülmesinden dolayı sıklıkla atlanabilir. Koruk ve ark.'nın [7] sunduğu tetanoz olgusunda da hasta defalarca doktora başvurmuş ve son gittiği doktor tarafından psikiyatri polikliniğine yönlendirilmiştir. Bizim olgumuzun hastanede yatışı esnasında semptomlarının ortaya çıkması, ilk esnada konversiyon olarak düşünülmesine rağmen tetanoz tanısının erken konmasina neden olmuştur.

Sonuç olarak; tetanoz nadir görülmesinden dolayı birçok hekim tarafından atlanarak geç tanı konulan bu nedenle mortalitesi artan bir hastalıktır. O yüzden hekimlerin kasılmaları olan hastalarda bu tanıyı atlamaması gerekir. Ayrıca uygun immünizasyon için özellikle acil servis ve sağlık ocağı çalışanlarının bilgilendirilmesi önemlidir.

\section{Kaynaklar}

1. Güneysel Ö, Sarıtemur M. Tetanoz: Klinik yaklaşım ve korunma. Akademik Acil Tip Derg 2006; 4: 48-53.

2. Bleck TP, Mandell GL, Bennet JE, Dolin R. Clostridium tetani (Tetanus). Mandell, Douglas, and Bennett's Principles and Practice of Infectious Disease. 6th ed. Philadelphia: Elsevier, Churchill Livingstone 2005: 2817-22.

3. Cook TM, Protheree RT, Handel JM. Tetanus: A reviev of the literature Br J Anesth 2001; 87: 477-87.

4. Ergonul O, Erbay A, Eren S, Dokuzoğuz B. Analysis of the case fatality rate of tetanus among adults in a tertiary hospital in Turkey. Eur J Clin Microbiol Infect Dis 2003; 22: 188-90.

5. Bartlett JG. Clostridium tetani. In: Gorbach SL, Bartlett JG, Blacklow NR, eds. İnfectious Diseases, 3th ed. Philadelphia. Lippincott Williams \& Wilkins 2004: 1796-9.

6. Rhee P, Nunley MK, Demetriades D, Velmahos G, Doucet JJ. Tetanus and trauma: A review and recommendations. J Trauma 2005; 58: 1082-8.

7. Koruk ST, Söğüt Ö, Karaağaç L, Çalışır C, Yalçın Ş. Unutulmaz hastalık: Çok hizlı seyreden bir tetanoz olgusu. JAEM 2013; 12: 174-7. 